\title{
Adapted Regulation Level's Flipped Classroom using Educational Data-mining
}

\author{
Mohamed Mimis \\ IRF-SIC, Ibn Zohr \\ University, Agadir \\ Morocco
}

\author{
Youssef Es-saady \\ IRF-SIC, Ibn Zohr \\ University, Agadir \\ Morocco
}

\author{
Mohamed El Hajji \\ IRF-SIC, Ibn Zohr \\ University, Agadir, \\ Morocco \\ SADS, Regional Center \\ for Education and Training \\ Professions-Souss Massa \\ (CRMEF-SM) \\ Morocco
}

\author{
Abdellah Ouled \\ Guejdi \\ IRF-SIC, Ibn Zohr \\ University, Agadir \\ Morocco
}

\begin{abstract}
Adaptation and individualization of learning is a major challenge when using flipped class as a teaching method. In this paper, we propose a recommendation system for flipped classroom to individualize learning in the classroom based on Data Mining algorithms. This system allows the teacher to predict a classification of learners before administering the tasks to be accomplished and the adapted teaching resources, using attributes related to the activity logs on the e-learning platform, to the online evaluations (Quiz) and to demographic data. The results show that the use of this model as a learning strategy optimizes the time of learning and improves the learner's performance.
\end{abstract}

\section{Keywords}

Educational data mining, flipped classroom, regulation of learning, adaptation, hybrid learning.

\section{INTRODUCTION}

The evolution of new technologies, particularly cloud computing, has improved access, sharing and storage of information. A new pedagogical model has been introduced called flipped classroom to improve the conditions of learning. Many educators encourage the coupling of both technology and the inverted class model in a hybrid learning strategy [1] [2].

The principle of flipped classroom is based on the modification of the traditional model of learning; Course elements and memorization exercises or direct course applications are visualized and performed online while the most difficult points and developments are dealt with in the presence of learners [3].

Figure 1 presents the three phases of the flipped classroom implementation namely the visualization of the video capsules out of class, the regulation, and the activities face-to-face (problem situations, case studies ...) in restricted groups or in the form of workshops. This strategy supposes that the learner will take control of his learning in terms of rhythm and control of the content [4] [5], in the other hand it will allow the teacher to use class time in different ways, such as regulation and by differentiation of learning, as well as booking more time for further learning.

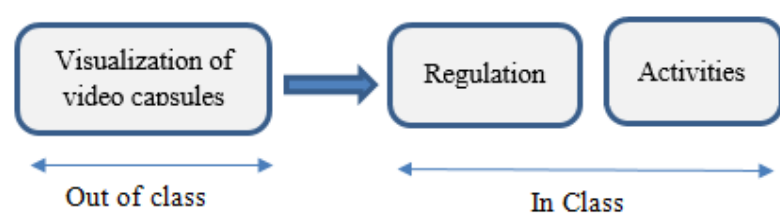

Fig 1: The three phases of the implementation of flipped classroom

The hybrid model proposed by El Hajji et al [1] improves the engagement of learners in their learning. However, during the regulation, other problems occur, particularly at choice of groups level.

The development of educational software as well as the use of the Internet has created a new context involving a large volume of information about learning factor [25]. Researchers are becoming more interested in data mining techniques in education and the development of the most appropriate algorithms for this kind of data [21], [30]. Indeed, a new field called Educational Data Mining (EDM) that has emerged as a field of research in recent years aims to apply data mining techniques to the educational data, which helps to discover many types of knowledge that can help stakeholders to make the best decisions.

The objective of this study is to identify groups where the apprentices belong based on learners' features, to support tutors to take the best decisions in regulation phase. Therefore, we have used data mining algorithms to better understand the learners and their ways of learning. The proposed system is based on prediction models, by detecting the most effective factors that work with learners' learning performance. It provides a new way of extracting hidden knowledge from the teacher and classifying learners into groups according to the level of regulation need. Our contribution can be summarized in:

- The collection and annotation of a set of data that is appropriate for the regulation of learning in flipped classroom

- The relevance study of the classifier.

In the following, we present the prediction 's model of student groups for flipped classroom regulation and the followed methodology. Then, we expose the first main results of our work and conclude with a conclusion. 


\section{PREDICTION MODEL OF REGULATION}

To implement flipped classroom, we have adopted the approach proposed by El Hajji et al [1] presented in Figure 2, where the regulation is divided into two phases:

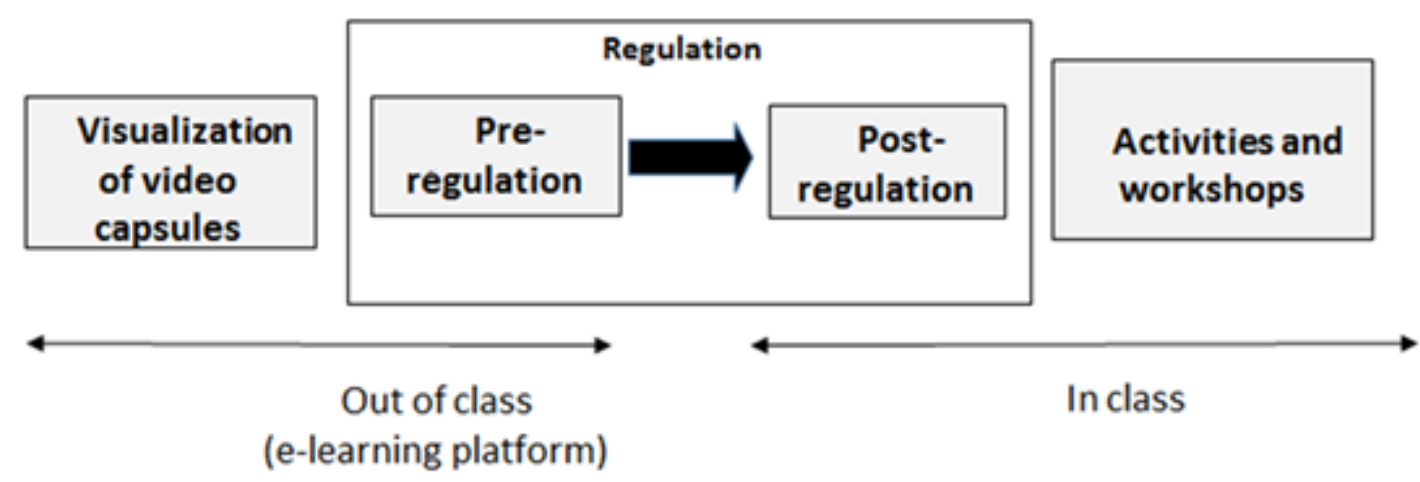

Fig 2: Phases of the implementation of the flipped class

\subsection{Phase 1 (Pre-regulation):}

This first phase is made at online platform in order to increase the regulation time and to take advantage of the technological and pedagogical practices. The online platform used does not only offer the establishment of media resources but also collaboration tools (wiki) and communication (forum, chat). This phase provides a set of descriptions related to the activity data of the learners.

\subsection{Phase 2 (post-regulation):}

The second phase is made in class, in which we exploit preregulation results to conduct a face-to-face regulation of learners.
A major result that emerged from the study of this approach shows a commitment of learners in the learning process. However, during the post-regulation, other problems occurred especially in terms of the choice of groups for regulation's phase. An analysis of these problems led us to carry out a study to develop a recommendation system using the techniques of the EDM. The system allows to help tutors make good decisions in the learning process by suggesting different alternatives. The figure 3 shows the architecture of the proposed system

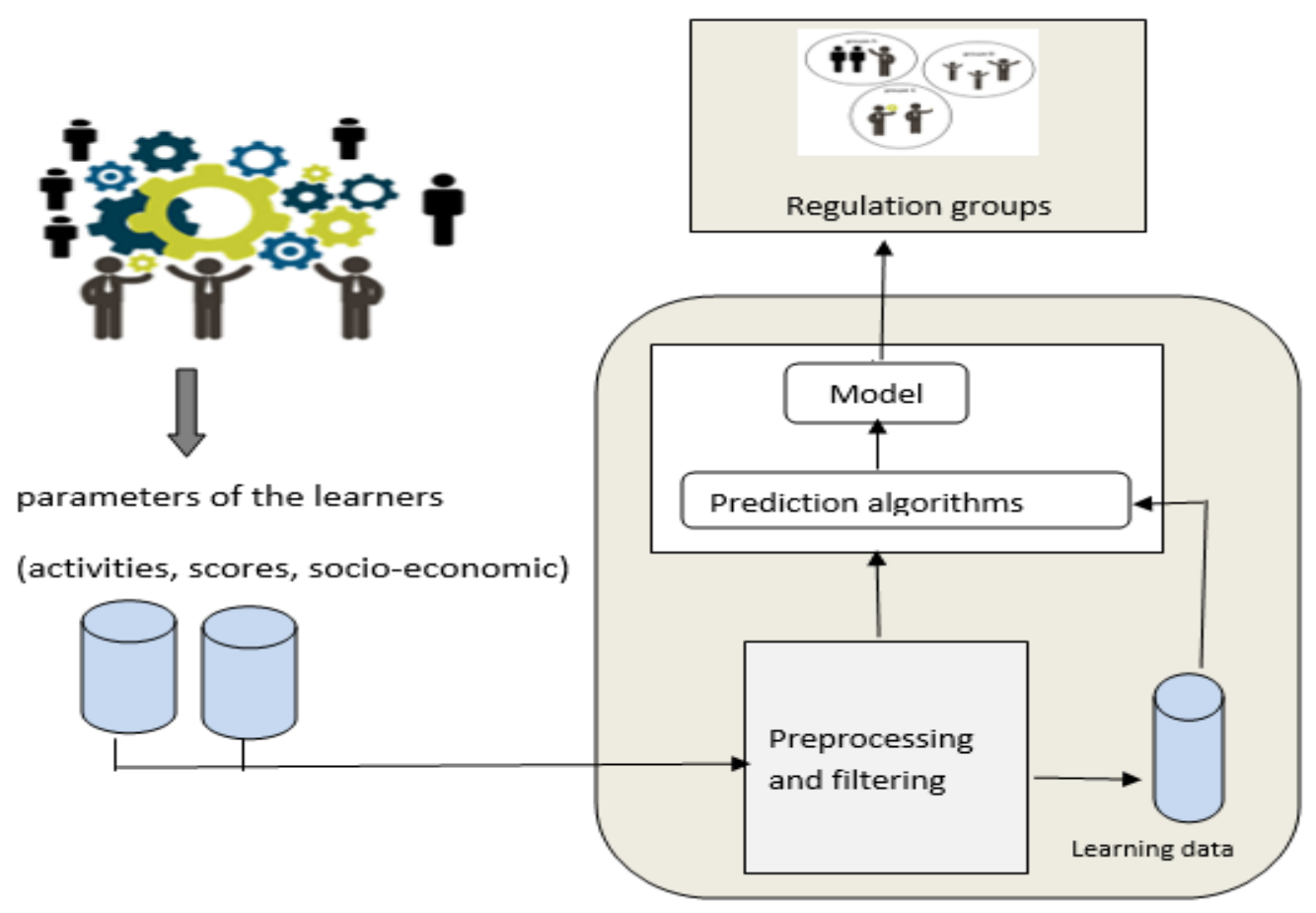

Fig 3. Regulation system' architecture. 


\section{METHODOLOGY}

Each educational data mining technique serves a different purpose depending on the modeling objective. The two most common modeling objectives are: descriptive models and predictive models. In descriptive models, hidden information present in the data is highlighted (e.g., clustering, association rules, sequence discovery, ...) whereas in predictive models, new knowledge is extrapolated from current information [26]. In order to develop the prediction models, we adopted the following methodology:

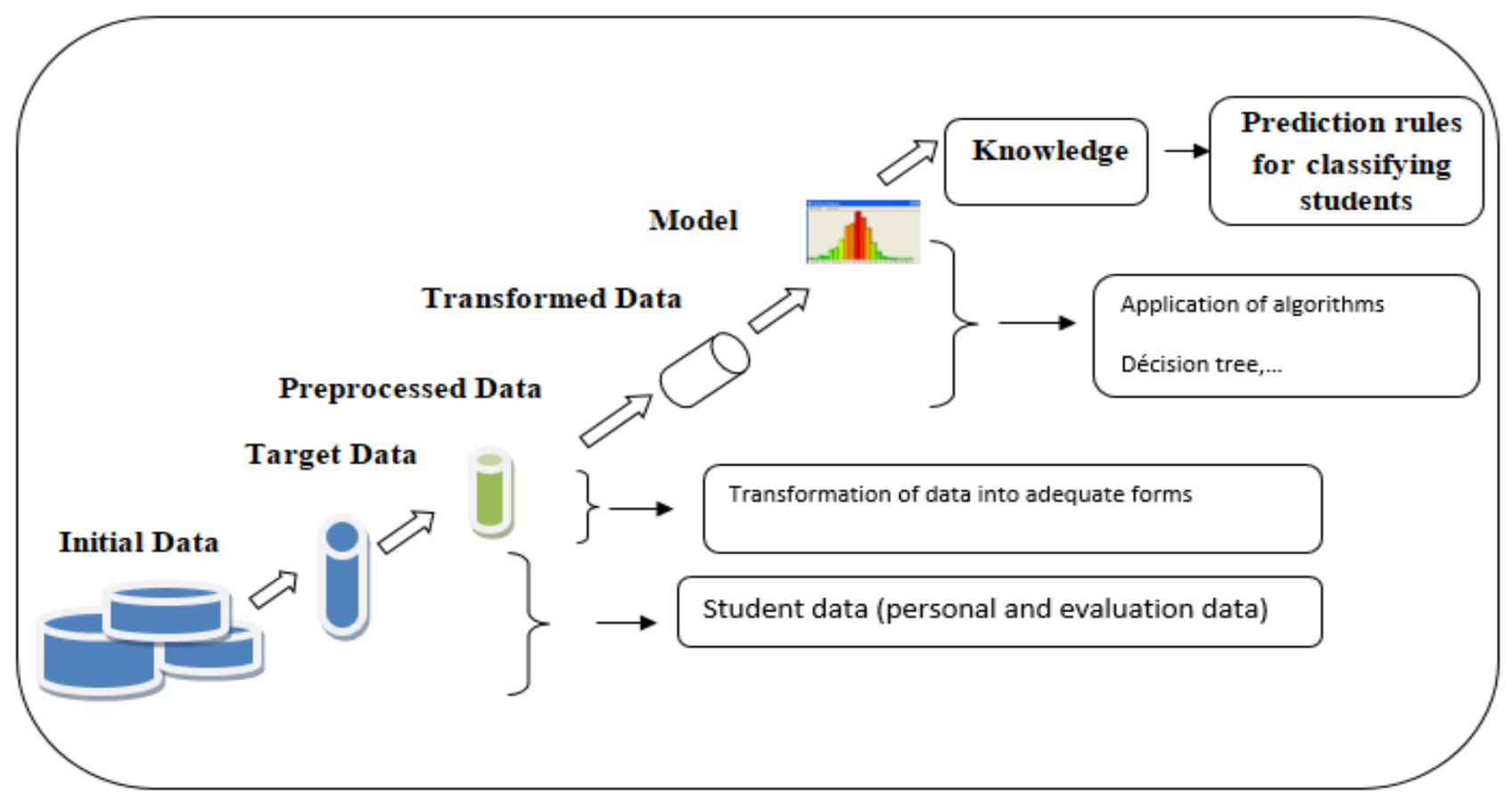

Fig4. The Stages of the development of the model.

To generate model to predict and classify learners' groups, we use different algorithms classifiers: Decision Trees, Neural Networks and Naive Bayes:

\subsection{Decision trees}

Decision trees are common procedures today, which provide a rapid and effective method for classifying and visualizing results. It represents a set of classification rules in a tree form. There are several learning algorithms, for example: ID3 [28]; [29]; CART [22]. The basic idea in all algorithms is to partition the attribute space into branches and leaves until the data are classified by satisfying a stopping condition [24].

\subsection{Neural networks}

The neural network is a set of interconnected nodes. The nodes of a layer are connected to all the nodes of the next level [31]. In the literature, there are several architectures of neuron networks. In this work, we chose a multilayer perceptron architecture using retro gradient propagation [32]. This network consists of three layers of neurons: an input layer, an output layer and a hidden layer.

\subsection{Bayesian naive algorithm}

Bayesian Naive is a classification method based on the Bayes theorem [27]. It is called naive because it simplifies the problem by using two important assumptions: it assumes that the prognostic attributes are conditionally independent, and assumes that there are no hidden attributes that could affect the prediction process. This classifier represents a promising approach to the probabilistic discovery of knowledge.

\section{RESULTS}

The data was collected from activity logs on the Blackboard e-learning platform, online assessment data (Quiz) and learner demographic data. In this section, we present the first results that we have obtained from online learners' activities and in the classroom.

To have more information about the peaks of the connection to the platform, we have done a sweeping per hour for several days. The statistical average of the number of connected persons is presented in figure 5 .

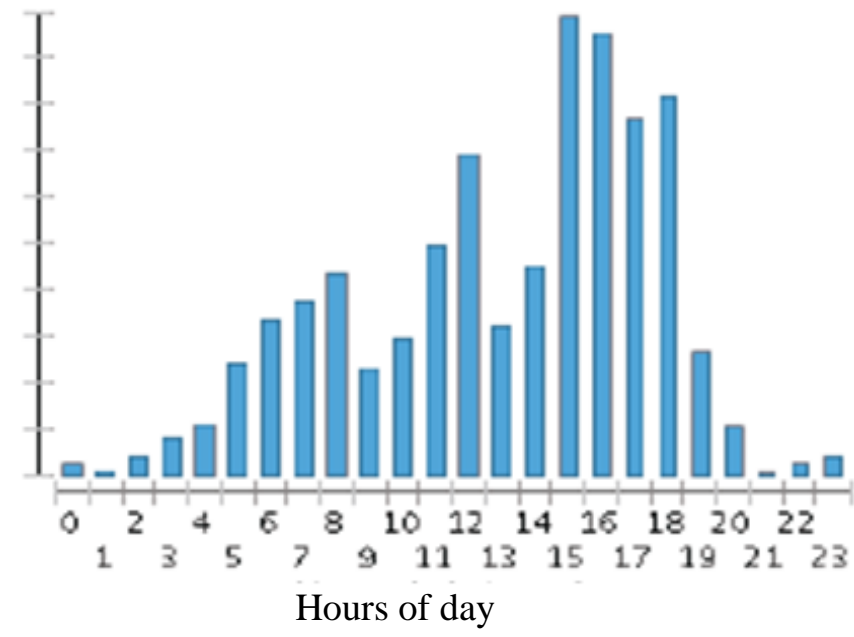

Fig5. Histogram of activities during the day 
We have compared, tested and analyzed the database with the three classifiers (C4.5 decision tree (J48), Naïve Bayes and Neural Networks) on available attributes. The following table shows the result of our first experience.

Table 1. Classification comparison results

\begin{tabular}{|c|c|c|c|}
\hline $\begin{array}{c}\text { Classificatio } \\
\text { n algorithm }\end{array}$ & (Accuracy) & Precision & Recall \\
\hline C.45 (J.48) & $76.09 \%$ & $82.54 \%$ & $73.93 \%$ \\
\hline Naïve Bayes & $91.30 \%$ & $88.33 \%$ & $93.48 \%$ \\
\hline $\begin{array}{c}\text { Multiplayer } \\
\text { Perception }\end{array}$ & $84.78 \%$ & $87.04 \%$ & $83.92 \%$ \\
\hline
\end{tabular}

The results clearly show that Naïve Bayes is the best classifier among the three classifiers tested, but decision trees have several advantages in our application: (1) decision trees require little data preparation; (2) the rules derived from decision trees are explicit and verifiable by an expert; (3) Because of their intelligibility, the rules can be used to improve the knowledge of algorithms and their contexts.

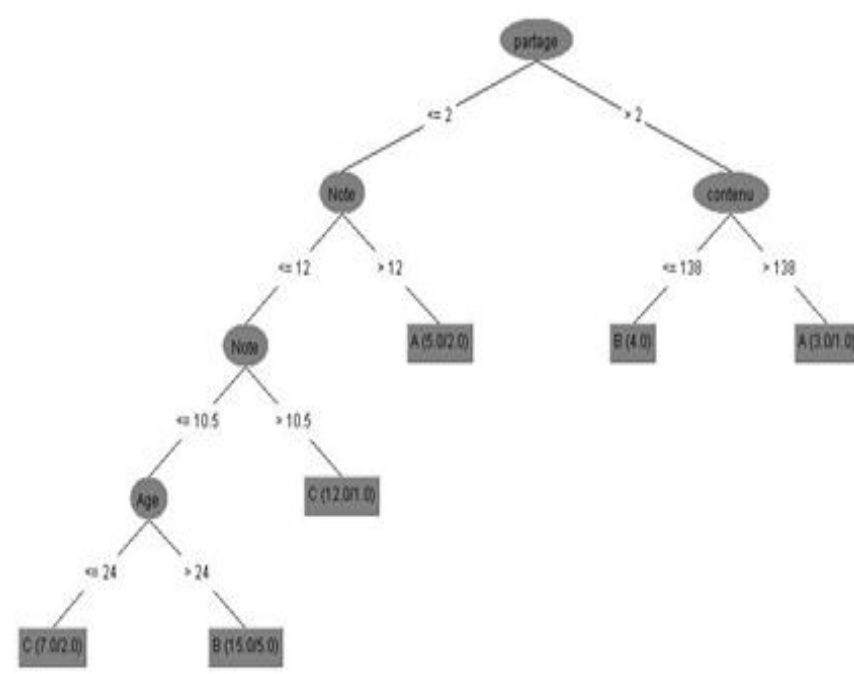

Fig6. A decision tree obtained by the $\mathbf{C 4 . 5}$ algorithm

\section{CONCLUSION}

In this work, we have proposed an approach to learning adaptation for flipped classroom. The recommendation system can classify learners to groups using prediction models. The results clearly show that Naïve Bayes is the best classifier among the three classifiers tested, but learning decision trees have several advantages in our model. The rules generated by decision trees provide in-depth knowledge for the teacher to make good decisions about improving learning differentiation. A comparative study using various decision-making structures needs to be explored. Other parameters concerning learners such as endurance, behavior, motivation and social networks are to be introduced and analyzed. Future work also involves generalizing the study to improve the accuracy of adopted models and algorithms.

\section{REFERENCES}

[1] Bowman, M., Debray, S. K., and Peterson, L. L. 1993. Reasoning about naming systems.

[2] Ding, W. and Marchionini, G. 1997 A Study on Video Browsing Strategies. Technical Report. University of Maryland at College Park.

[3] Fröhlich, B. and Plate, J. 2000. The cubic mouse: a new device for three-dimensional input. In Proceedings of the SIGCHI Conference on Human Factors in Computing Systems

[4] Tavel, P. 2007 Modeling and Simulation Design. AK Peters Ltd.

[5] Sannella, M. J. 1994 Constraint Satisfaction and Debugging for Interactive User Interfaces. Doctoral Thesis. UMI Order Number: UMI Order No. GAX9509398., University of Washington.

[6] Forman, G. 2003. An extensive empirical study of feature selection metrics for text classification. J. Mach. Learn. Res. 3 (Mar. 2003), 1289-1305.

[7] Brown, L. D., Hua, H., and Gao, C. 2003. A widget framework for augmented interaction in SCAPE.

[8] Y.T. Yu, M.F. Lau, "A comparison of MC/DC, MUMCUT and several other coverage criteria for logical decisions", Journal of Systems and Software, 2005, in press.

[9] Spector, A. Z. 1989. Achieving application requirements. In Distributed Systems, S. Mullender.

[10] El Hajji, M., et al., New Blended Learning Strategy Based on Flipped-Learning for Vocational Work-Linked Training. Journal of Education and Practice, 2016. 7(36): p. 126-130.

[11] Plasencia, A. and N. Navas, MOOCs, the flipped classroom, and Khan Academy practices: The implications of augmented learning, in Innovation and Teaching Technologies. 2014, Springer. p. 1-10.

[12] Fine, J. and C. Vermandele, La statistique dans le secondaire et retour sur les MOOCs. Statistique et Enseignement, 2014. 5(1): p. 1-3.

[13] Alvarez, B., Flipping the classroom: Homework in class, lessons at home. The Education Digest, 2012. 77(8): p. 18.

[14] Fulton, K., Upside down and inside out: Flip your classroom to improve student learning. Learning \& Leading with Technology, 2012. 39(8): p. 12-17.

[15] Baker, R., Data mining for education. International encyclopedia of education, 2010. 7(3): p. 112-118.

[16] Peraya, D., F. Lombard, and M. Bétrancourt, De la culture du paradoxe à la cohérence pédagogique. Bilan de 10 années de formation à l'intégration des TICE pour les futurs enseignants du primaire à Genève. Formation et pratiques d'enseignement en question, 2008(7) : p. 1128.

[17] Laveault, D. La régulation des apprentissages et la motivation scolaire. in Document présenté au Ministère de l'Éducation, du Loisir et du Sport.[En ligne] www. mels. gouv. qc. ca/REFORME/conf/conflaveault. pdf (Consulté le 26 janvier 2009). 2000. 
[18] Quinlan, J.R., C4. 5: programs for machine learning. 2014: Elsevier.

[19] Frank, E., et al., Naive Bayes for regression. Machine Learning, 2000. 41(1): p. 5-25.

[20] Vandamme, J.P., N. Meskens, and J.F. Superby, Predicting academic performance by data mining methods. Education Economics, 2007. 15(4): p. 405-419.

[21] Baker, R. S. and K. Yacef (2009). "The state of educational data mining in 2009: A review and future visions." JEDM-Journal of Educational Data Mining 1(1): 3-17.

[22] Breiman, L., J. Friedman, C. J. Stone and R. A. Olshen (1984). Classification and regression trees, CRC press.

[23] Breuel, T. and F. Shafait (2010). AutoMLP: Simple, effective, fully automated learning rate and size adjustment. The Learning Workshop, Utah.

[24] Brijain, M., R. Patel, M. Kaushik and K. Rana (2014). "A survey on decision tree algorithm for classification."

[25] Castro, F., A. Vellido, À. Nebot and F. Mugica (2007). "Applying data mining techniques to e-learning problems." Evolution of teaching and learning paradigms in intelligent environment: 183-221.
[26] Etchells, T. A., À. Nebot, A. Vellido, P. J. Lisboa and F. Mugica (2006). Learning what is important: feature selection and rule extraction in a virtual course. ESANN.

[27] Frank, E., L. Trigg, G. Holmes and I. H. Witten (2000). "Naive Bayes for regression." Machine Learning 41(1): 5-25.

[28] Quinlan, J. R. (1986). "Induction of decision trees." Machine learning 1(1): 81-106.

[29] Quinlan, J. R. (2014). C4. 5: programs for machine learning, Elsevier.

[30] Romero, C. and S. Ventura (2013). "Data mining in education." Wiley Interdisciplinary Reviews: Data Mining and Knowledge Discovery 3(1): 12-27.

[31] Witten, I. H., E. Frank, M. A. Hall and C. J. Pal (2000). Data Mining: Practical machine learning tools and techniques, Morgan Kaufmann.

[32] Y. Es-Saady, A. Rachidi, M. El Yassa, D. Mammass, Amazigh Handwritten Character Recognition based on Horizontal and Vertical Centerline of Character, International Journal of Advanced Science and Technology, vol. 33, pp. 33-50, August, 2011. 